\title{
Present/Forthcoming: Tracing imagined waters and their inhabitants
}

Much of my time working in collaboration with Jon Lindqvist was spent watching for (and noting) traces and trace makers on a street corner in Musselburgh, South Dunedin. The suburban site endures the same issues as much of the region's hazardscape: "low-lying topography, underlain by poorly consolidated sediment... proximity to the ocean and harbour, a shallow water table with strong connectivity between sea and groundwater, and an exposure to heavy rainfall events" ${ }^{1}$, as described by the Otago Regional Council's 2016 Natural Hazard report. In models of surface ponding in relation to increasing sea levels, the street corner finds itself under increasingly colourful pools. Simulated ripples, banded with new hues for each $0.2 \mathrm{~m}$ of water depth, predict up to $0.5 \mathrm{~m}$ of flooding in Musselburgh with a $0.6 \mathrm{~m}$ mean sea level rise, ${ }^{2}$ a hazard that presents the "greatest risk" to its surrounding communities (Figure 1). ${ }^{3}$ At the corner most deeply saturated, I watched for movements amongst a bush of daisies as they shift in the wind's currents. Should the same flowers be scratching against sediment, suspended or carried by water, what marks would they leave? In trace fossil terms, they may follow the suit of seaweed passively moved by waves and produce tool marks, forming one of many categories of pseudofossils. Though distinct from true animal ichnofossils in their origins, the pseudofossil, in its process of making, retains scientific interest. This is emphasized as much by Adolf Seilacher in "Trace Fossil Analysis," with the pseudofossil maintained as a valuable "historical document that records sedimentary, diagenetic, or tectonic processes and environmental conditions." ${ }^{4}$

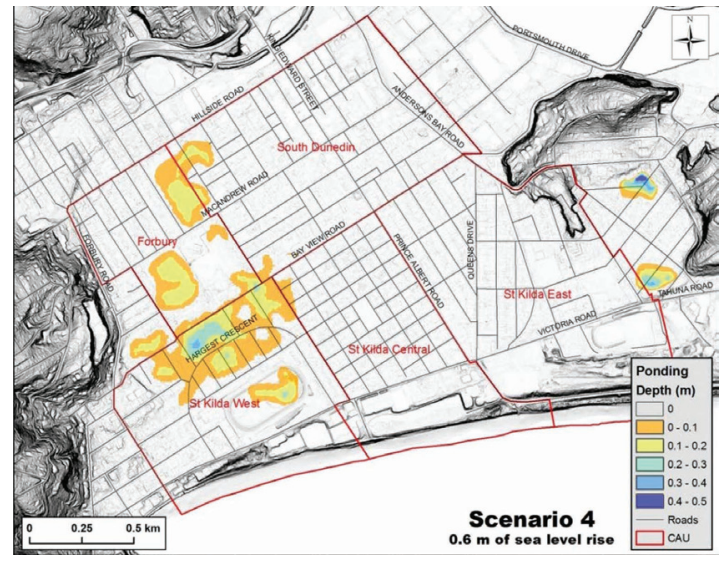

Figure 1. Above-ground ponding for $0.6 \mathrm{~m}$ of mean sea level rise, relative to the 2003-2015 average. The site of the project (Musselburgh) is located top right of the map, with the deepest predicted ponding visible in dark blue. 
Extending the fossil's status as Earth process, record, and narrative, I looked to Jussi Parikka's "Geology of Media." Laying contemporary media out, over, and through its earliest Earth-produced forms, Parikka identifies fossils as "buried temporal object[s]...gateway[s] to past time as monument[s] in the present." ${ }^{5}$ The signals offered by fossils document the planet's condensed "historicity" and legitimise the earth as "library as well as recording medium." ${ }^{6}$ The marks in my notebook were of course their own recording medium. Noted with dates and times, they offered recounts of the street corner in specific terms. Observation was mixed with speculation; my personal catalogue of marks and translation tools blended with memories of Seilacher's trace fossil diagrams to equate the paths of gulls above and bees below as pseudo-traces on paper, upon paper, buried in slabs of notebooks. This application of drawing and indeed in most observational drawing (layering seen understandings and interior logic into thick crusts of impression) was steeped in the traditions of all time based-media, described by Siegfried Zielinski as "techniques for reproducing existing worlds and artificially creating new ones." Zielinskis' proposition is aptly referenced at the introduction of Parikka's "Planetary Memories," where functions of time media are used in analysis of political and cultural strategies for regarding the multitemporal position of eco-crises, not just as a present dilemma but a "future that acts on the now."

South Dunedin's present and future trials in the wake of climate crisis are forecast regularly and increasingly. A multitemporal eco-crisis is one both withdrawing and forthcoming. We sit within uncertain climate and in uncertain positions. The records of change retained and revealed by Earth are by nature selective, our exposure to its narratives reliant not only on the passage of time but its effects on our surroundings and our capacities for reading them. Ichnology as communication tool challenges our capacities for reading traces and imagining their originators, for grappling with such uncertainty. Animals, plants, minerals, and water, as equal agents of creation in the fossil chapter, are without explicit anatomy as identifying cue (acknowledged instead for their movements, interactions and behaviours upon recording grounds). Ichno-fossils are documents of the unseen, their nonhuman makers withdrawing from easy definition and linear narratives. Drawing, as kindred withdrawing and seeking state, offered itself in this instance as a tool for actively recognizing and reading such speculative trace making. In this project, observations and drawings at threatened sites were further manipulated in emulation of ichnological processes to offer up pseudofossils as drawing/site/time interfaces (time media) through which quiet, local sites of impending flux can be reckoned with.

My drawings made in Musselburgh were inscribed into clay, forming negative moulds into which paper and charcoal could be pressed. Recycled paper pulp made into sheets using a mould, deckle, and vats of water, emulated its own form of sedimentation. Settling into the crevices of drawing records, to produce new echoes of the site, the marks raised out of the paper ground (Figure 2). As each wetted sheet was laid on top of the pile, the paper settled again, sinking into or lifted by the layers below it. An accretion was formed, a pseudofossil whose peaks and troughs speak to the rhythms of a future urban pond (Figure 3). The "fossilized" drawings, now serving a three-dimensional role in the accreted mass, moved from immediate observation and responsive translation of real time encounters, towards a state of evidence (Figure 4 and 5). As Terry Rosenberg describes in his writing on ideational drawing, the drawings became "a feature in a history of the process", the processes' history being one of time and attention. ${ }^{9}$ Accompanying the accretion was video documentation of individual paper sheets inside the pseudofossil, cut alongside sequences of cellphone footage taken during the same drawing trips (Figure 6). As 


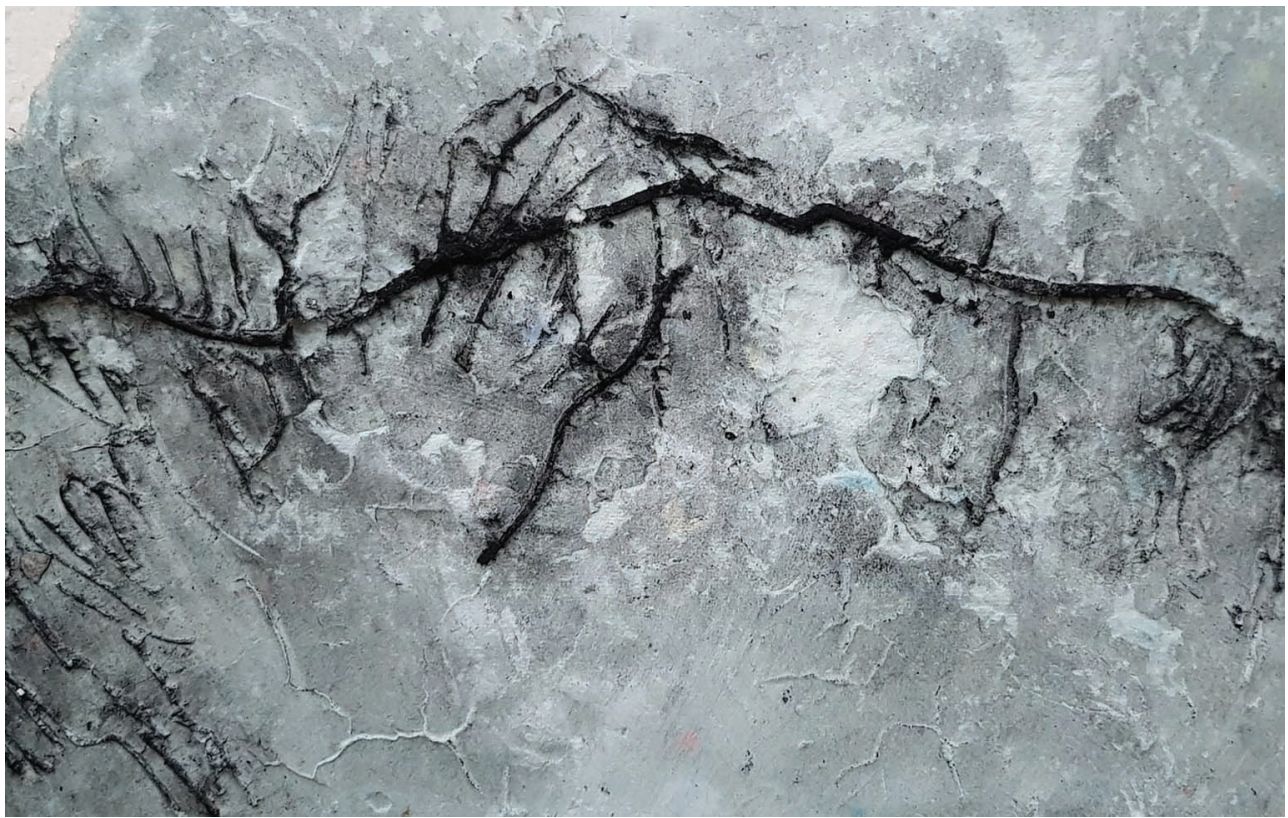

Figure 2. A trace of finch movements through the treeline above the street corner,

"fossilized" in pressed charcoal and recycled paper. Photograph: Madison Kelly.

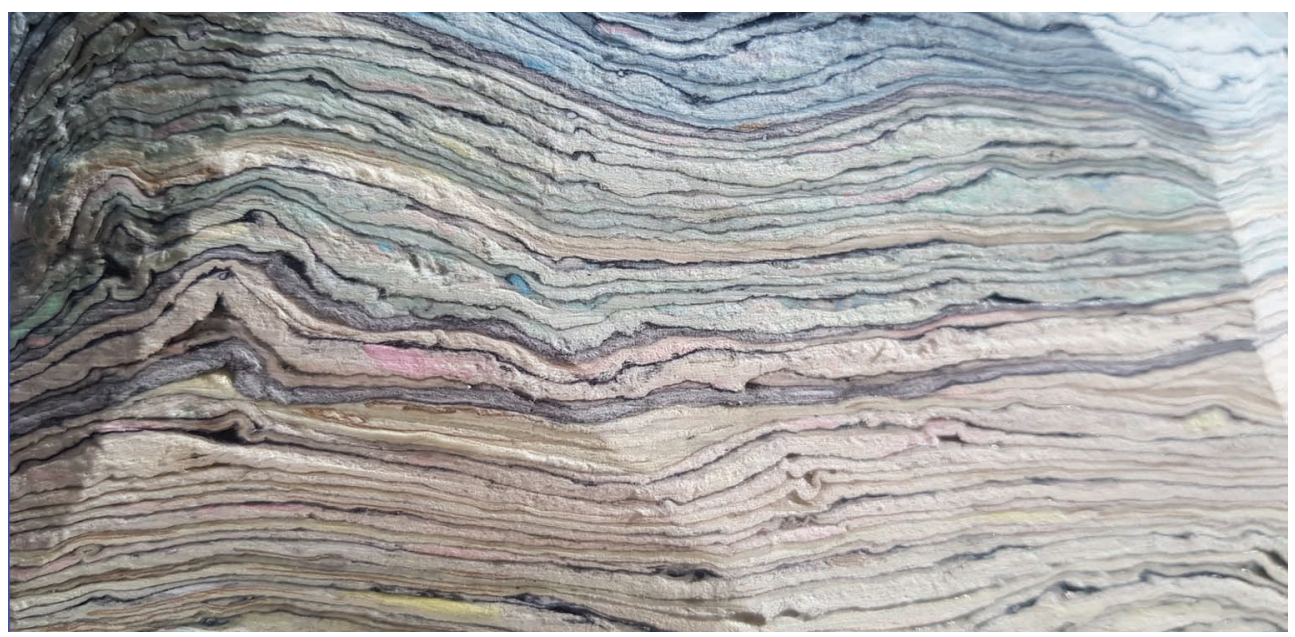

Figure 3. Cross section through the final "accretion" of paper pseudofossils. Paths of travel are visible as folds and bumps in the paper sheets. Photograph: Madison Kelly. 
Groys reminds us, "documentation is neither the making present of a past... nor the promise of a coming." ${ }^{10}$ The video accompanied the block as virtual guide for an otherwise withdrawing archive, a digital tether to the site in the present, as well as the accreted attentions towards that present.

Ichnofossils present us with records of nonhuman action, muddled and thrown out by the planet and its variations. What changes are occurring in South Dunedin? Where and when will waters rise, and which paths of movement, whose paths of encounter will be affected in return? Present/forthcoming offers consideration in ichno-terms, where trace-making and its accumulation becomes ground upon which local human/nonhuman connections can be recorded, and the implications of their mingling speculated upon. Drawings manifested physically, slowly, incrementally, upon unsettled and settling paper (both physical and digital) hope for a thinking on enfolding sites - threatened ecologies where Richard Grusin's “premediation” can be approached as a "medial preemption that works by way of creating a constant atmosphere of possible future scenarios impinging upon us now." ${ }^{11}$ As Parikka elaborates in "Planetary Memories", the dilemma of approaching to-be-extinct or to-be-erased communities becomes "less a predetermined event than a mediated future-present."12

Present/forthcoming was not only a collaboration between my studio practices and the workings of Jon's ichnology research, but between me and the street corner, engaging with its winds, plants, insects, soils, residents, sounds, and birds. Between attending to the present and exploring processes that can think upon its future, I have felt in this iteration of the art/science initiative the "bumptious diversity" of Donna Haraway's art science activisms, those that encourage us to "relate, know, think, world, and tell through and with other stories, worlds, knowledges, thinkings... [as] do all the critters of Terra." ${ }^{13}$

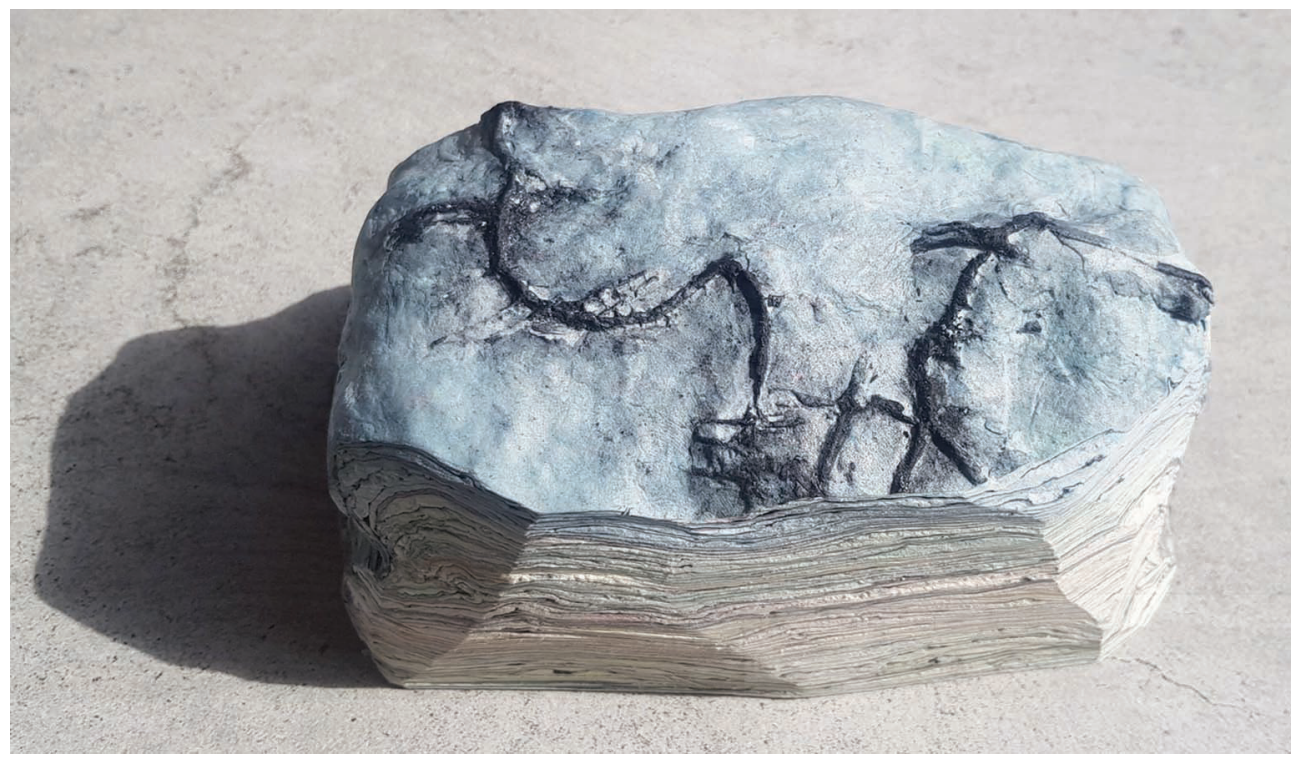

Figure 4. Top-down view of the final accretion, with most recent trace observation still visible at the uppermost layer. Photograph: Madison Kelly. 


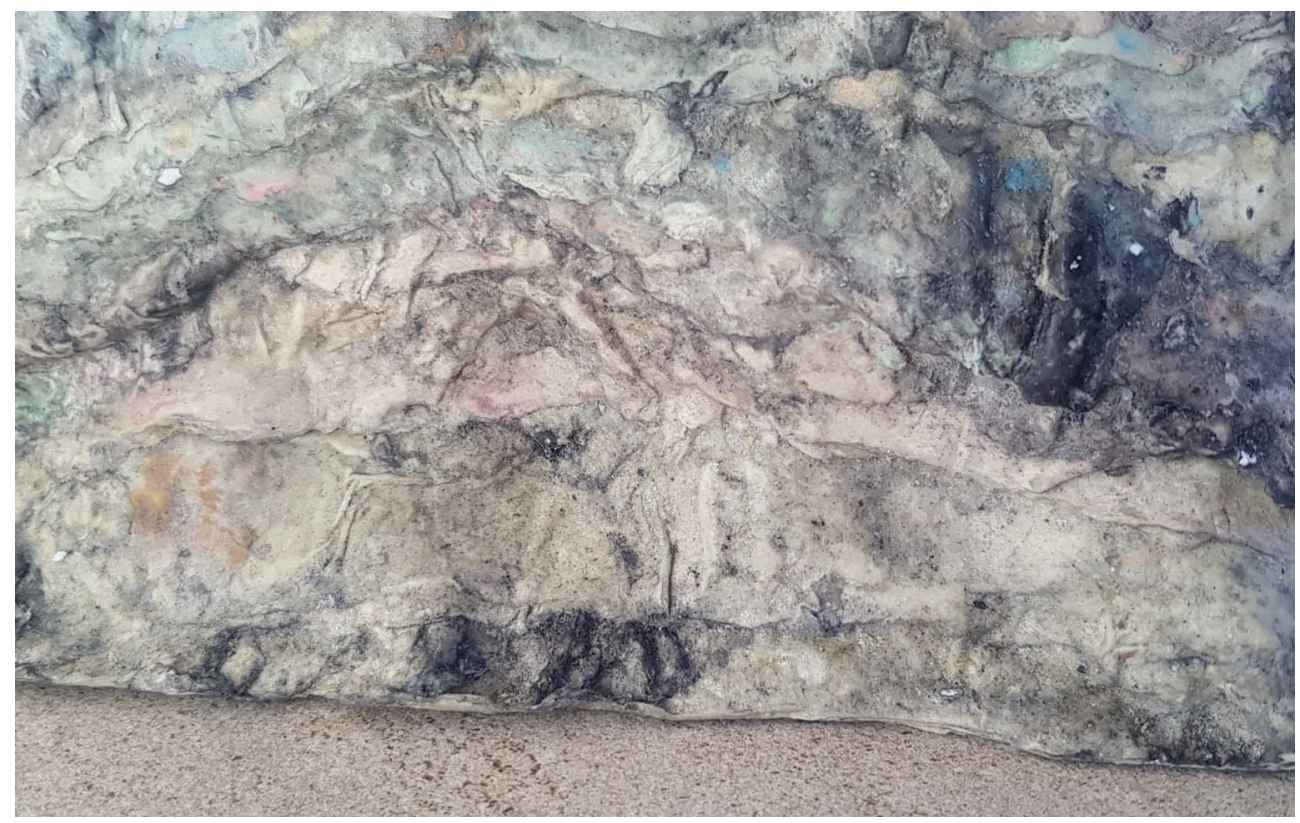

Figure 5. The accreted paper and charcoal still visible on the other side of the object. Photograph: Madison Kelly.

Figure 6. Digital documentation of traces made from flowers at the Musselburgh site, alongside cellphone footage of the same flowers taken whilst drawing. Photograph: Madison Kelly.

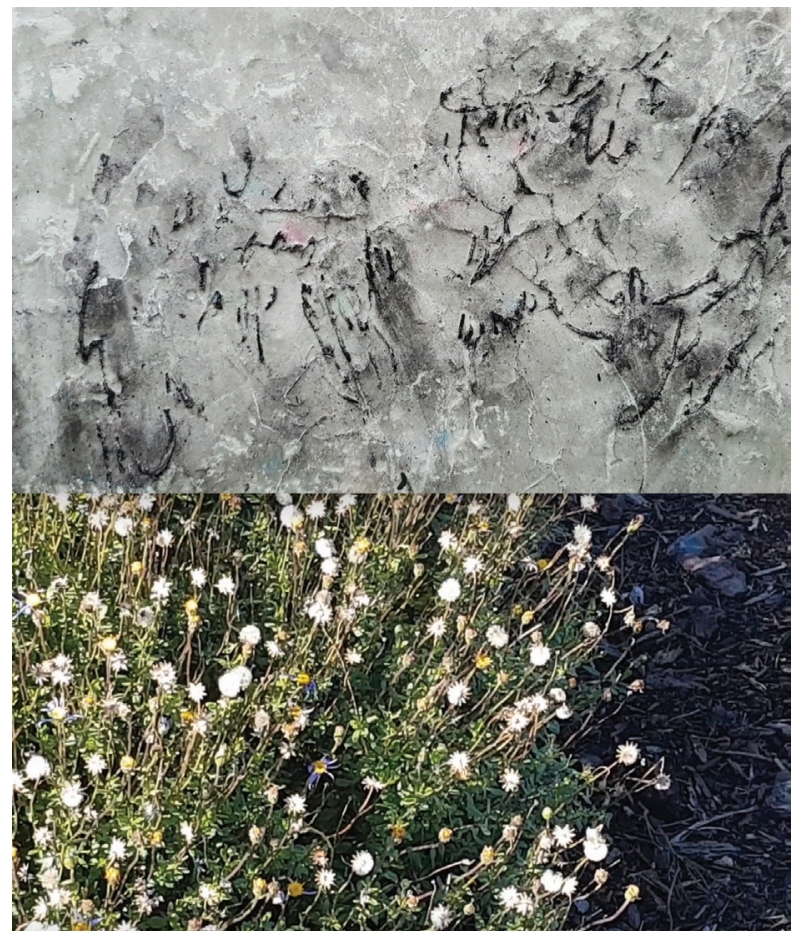


Madison Kelly graduated with a BVA (Hons) in drawing from the Dunedin School of Art in 2017. Her work seeks to question contemporary human/nonhuman relations through a broadened drawing practice, with a focus on drawing's role in recording attentions and understanding towards threatened species and sites over time.

1. Michael Goldsmith and Sharon Hornblow, The Natural Hazards of South Dunedin (Dunedin, New Zealand: Otago Regional Council, July 2016), 1.

2. Ibid, 52.

3. Ibid

4. Adolf Seilacher, Trace Fossil Analysis (Berlin: Springer, 2007), 159. See also, tool marks from plant materials, as described in Seilacher's Trace Fossil Analysis (p 165, plate 57).

5. Jussi Parikka, A Geology of Media (Minneapolis: University of Minnesota Press, 2015), 116.

6. Ibid, 116.

7. Zielinski, Deep Time of Media: Toward an Archaeology of Hearing and Seeing by Technical Means, trans. Gloria Custance (Cambridge: MIT Press, n.d.), 31.

8. Jussi Parikka, "Planetary Memories: After Extinction, the Imagined Future," in Richard Grusin, ed., After Extinction (Minneapolis: University of Minnesota Press, 2018), 36.
9. Terry Rosenberg, "New Beginnings and Monstrous Births: Notes Towards an Appreciation of Ideational Drawing," in Writing on Drawing: Essays on Drawing Practice and Research (Bristol: Intellect Books, 2008), 123.

10. Boris Groys, "Art in the Age of Biopolitics: From Artwork to Art Documentation," trans. Steven Lindberg, Documenta 11-Platform 5: Exhibition Catalogue, 2002, 108.

11. Parikka, "Planetary Memories," 29.

12. Ibid, 29.

13. Donna Haraway, "Symbiogenesis, Sympoiesis, and Art Science Activisms for Staying with the Trouble," in Arts of Living on a Damaged Planet (Minneapolis: University of Minnesota Press, 2017), 45. 